\title{
"Tem NEM tempo de respirar"; o papel da prosódia na dramatização da experiência pessoal em narrativas orais
}

Registramos nosso agradecimento a Diogo Pinheiro, pela leitura atenciosa do texto e comentários valiosos à articulação deste artigo.

\section{TALITA De Oliveira}

Doutora em Letras. Centro Federal de Educação Tecnológica Celso Suckow da Fonseca, Brasil. talitaoli@hotmail.com

Resumo: O presente artigo focaliza o papel da prosódia como importante dispositivo de avaliação encaixada (LABOV, 1972) que confere carga dramática e emocional à narrativa, contribuindo na construção do self do narrador. Considerando as narrativas como performances (BAUMAN, 1986; RIESSMAN, 2008), o trabalho focalizará a performance narrativa/identitária de três alunas de uma escola de nível médio-técnico que dramatizam o cotidiano de exaustão física de suas atividades estudantis. Ao encenarem sua rotina de estudos em tempo integral, as alunas fazem uso de recursos prosódicos, resultando na dramatização de um cotidiano marcado pela escassez de tempo e pelo cansaço corpóreo.

Palavras-chave: Narrativa; performance; recursos prosódicos

\section{Liana de AndRade Biar}

Doutora em Letras. Centro Federal de Educação Tecnológica Celso Suckow da Fonseca, Brasil. lianabiar@gmail.com

Abstract: This article examines the role of prosody as an important type of embedded evaluation (LABOV, 1972) which gives dramatic and emotional impact on narrative and contributes to the construction of the narrator's self. Considering narratives as performances (BAUMAN, 1986; RIESSMAN, 2008), the study focuses on the narrative/identity performance of three students of a secondary vocational school which dramatizes the physical exhaustion of their daily student activities. As they perform their full-time studies routine, the students make use of prosodic devices, resulting in the dramatization of a daily life marked by the lack on time and body fatigue.

Key-Words: Narrative, performance, prosodic devices 



\section{Introdução}

As reflexões sobre prosódia aparecem de modo razoavelmente pulverizado na literatura sociointeracionista a partir principalmente da noção de pistas de contextualização, conforme elaborada por Gumperz (1982). Usadas para inferir propósitos interacionais de interlocutores engajados em uma situação de comunicação, essas pistas podem ser definidas como constelações de traços linguísticos, paralinguísticos ou prosódicos, presentes nas superfícies da conversa, de que os interlocutores lançam mão nas interações cotidianas e que o/a analista tenta recuperar para fins de interpretação daquilo que extrapola o conteúdo proposicional do que é dito e ouvido cotidianamente.

Nos estudos sobre narrativas conversacionais, objeto do presente artigo, a prosódia tem sido abordada experimentalmente, para validar as intuições interacionistas sobre a estrutura do discurso narrativo (OLIVEIRA, 2002). Mas, se estivermos preocupados com a emergência interacional das narrativas orais e seus efeitos de sentido - como é de fato uma preocupação deste trabalho -, então é em Labov (1972), pioneiramente, e em seus sucessores que encontraremos um tratamento dos aspectos prosódicos a partir de seu valor expressivo sinalizador de avaliações implícitas que interlocutores fazem de si, do outro e do mundo ao seu redor.

Considerada uma forma de organização básica da experiência e da memória humanas (BASTOS, 2005; BRUNER, 1997; MOITA LOPES, 2001), a narrativa corresponde a um notório instrumento de produção do significado e de identidades sociais. Boa parte da pesquisa contemporânea nas Humanidades, nas Ciências Sociais e nos Estudos da Linguagem tem chamado atenção para a centralidade das narrativas na constituição dos sujeitos e da realidade social, advogando-se, cada vez mais, que, para se compreender 
o mundo social, é preciso ouvir e estudar as histórias das pessoas que vivem nesse mundo.

Diferentes modelos teóricos e taxonomias têm procurado compreender o que é uma narrativa e que elementos estruturais formais a caracterizam como tal. Em pesquisas contemporâneas, entretanto, é notório e crescente o interesse em se estudar não apenas os constituintes estruturais das histórias, mas, também, o que significa contá-las. Segundo Riessman (2008, p.11), os chamados analistas da narrativa têm procurado questionar "a intenção e a linguagem - como e por quê incidentes são narrados, não apenas o conteúdo referenciado pela linguagem". Assim, os interesses de pesquisa têm se voltado para o modo como nos utilizamos de habilidades narrativas para (re)construir eventos, atribuir significado a eles e fazer emergir nossas identidades sociais face à presença da plateia no aqui e agora da interação (GOFFMAN, 2007 [1975]).

O presente artigo objetiva focalizar o papel da prosódia como um importante dispositivo de avaliação encaixada (LABOV, 1972) e potente recurso que confere carga dramática e emocional à narrativa e que contribui, sensivelmente, na construção do self do narrador. A partir doconceitodeperformance(BAUMAN, 1986; RICHARDS, 1999; OLIVEIRA \& BASTOS, 2001; LANGELIER, 2001; RIESSMAN, 2008), as narrativas são aqui entendidas como atuações dramatúrgicas (GOFFMAN, 2007 [1975]) que dão forma às relações sociais cotidianas, dando visibilidade ao modo como as histórias são contadas e o que elas dizem sobre o narrador e ao grupo social a que pertence. Será focalizada a performance narrativa/ identitária de Joana, Kátia e Raquel, três alunas de uma escola de nível médio-técnico da rede federal de ensino que co-constroem uma narrativa cujo ponto (LABOV, 1972) é a dramatização do cotidiano de exaustão física constituinte de suas atividades estudantis. Ao encenarem 
sua rotina de estudos em tempo integral, as alunas lançam mão de recursos tais como alongamento de vogais, ênfase em sílabas e/ou palavras e alternância no ritmo de fala e na altura da voz. O resultado é a dramatização de um cotidiano marcado pela escassez de tempo e a vivificação do cansaço corpóreo experienciado pelas alunas.

Nesse sentido, este artigo pode ser compreendido como uma tentativa de desenvolver, ainda que embrionariamente, as bases fundamentais de um tratamento de certos aspectos prosódicos nos estudos interacionais sobre narrativas cotidianas, na tentativa de se estabelecer diálogo e intercâmbio fundamentais para se refinar métodos de identificação, transcrição e análise dos mecanismos suprassegmentais que constroem a performance narrativa.

\section{Da estrutura à práxis de se contar histórias}

Os estudos de William Labov (1972) abriram terreno para o desenvolvimento de pesquisas sobre narrativa não apenas nos Estudos da Linguagem, mas também em outros campos do saber (BASTOS, 2004). Com base em dados gerados em gravações de conversas em situação de entrevista, as pesquisas de Labov acarretaram inúmeras contribuições para a pesquisa sobre narrativas de experiência pessoal, especialmente no que tange à descrição de uma sintaxe narrativa. Os estudos labovianos sinalizam que "a fala conectada é ordenável e descritível em termos de sua estrutura e função" (JOHNSTONE, 2001, p.638), conferindo, assim, relevância à noção de sequencialidade temporal. Do mesmo modo, tem destaque, na chamada narrativa laboviana, a noção de reportabilidade. Segundo o autor, toda narrativa deve apresentar um ponto e referir-se a algo extraordinário, digno de ser contado. "O ponto da narrativa é sua razão de ser, é o motivo pelo qual ela é 
contada, o que está contido em sua mensagem central" (BASTOS, 2005, p.75; grifo da autora).

Das seis propriedades formais que caracterizam a narrativa laboviana - a saber: abstract (ou sumário), orientação, ação complicadora, avaliação, resolução e coda -, para os fins do presente artigo, daremos particular destaque à avaliação (grifo nosso), considerada por Riessman (1993) como "a alma da narrativa". Labov identifica dois tipos característicos de avaliação: a externa e a encaixada. Na avaliação externa, o narrador suspende o fluxo narrativo para dizer diretamente para seu ouvinte o quão desagradável, angustiante, perigosa ou satisfatória foi a experiência. Já na avaliação encaixada, é frequente o uso de recursos linguísticos como repetições e intensificadores lexicais, além de marcas de expressividade fonológica e prosódica (BASTOS, 2005). A avaliação "contém informação sobre a carga dramática ou o clima emocional da Narrativa e é usada para indicar o seu ponto" (ibid., p.76) e, por meio de recursos linguísticos de avaliação entre eles, a prosódia -, o narrador sinaliza como quer ser entendido pelos seus ouvintes.

Estudos mais recentes em torno das narrativas têm procurado rever criticamente os trabalhos pioneiros e tradicionais nos Estudos da Linguagem, enfatizando as lacunas deixadas pelos modelos teóricos de maior destaque e as especificidades do mundo social atual. No que diz respeito ao modelo narrativo proposto por Labov, alguns pesquisadores reconhecem a funcionalidade dos componentes descritos pelo autor, porém estabelecem algumas ressalvas quanto aos limites de sua teoria. Riessman (2008), por exemplo, reconhece a utilidade da análise estrutural da narrativa proposta por Labov, por "levar a linguagem a sério" (p. 103) e fornecer aos pesquisadores um ferramental analítico que os oriente na observação de como as pessoas se utilizam do discurso para construírem suas histórias. Por outro lado, a autora afirma 
que esse tipo de abordagem estrutural tende a enfatizar o nível micro (local) de análise em detrimento de aspectos macro da sociedade. Nesse sentido, a teoria laboviana é questionada por tratar a narrativa como uma estrutura formal autônoma em relação às práticas de se contar histórias (BASTOS, 2004), reduzindo a possibilidade de uma melhor compreensão sobre quem conta essas narrativas e sobre a sociedade que as contextualiza. Além disso, critica-se o modelo laboviano por minimizar, ou mesmoignorar (FABRÍCIO \& BASTOS, 2009), a relevância da participação da audiência na tessitura e interpretação das narrativas. Dessa forma, não se abre espaço para se considerar o caráter situacional e estratégico (OLIVEIRA \& BASTOS, 2001) das histórias que contamos, bem como o papel das performances narrativas/identitárias, conforme veremos a seguir.

\section{Performances narrativas e atuação dramatúrgica}

É tácita a inter-relação entre o ato de narrar histórias e a construção de identidades sociais, visto que o narrador posiciona-se moral e ideologicamente em relação aos episódios narrados e, simultaneamente, engaja-se na tessitura de sua auto-imagem. Conforme aponta Riessman (1993, p.11), "ao contar sobre uma experiência, também estou criando um self - como quero ser reconhecido por eles", pela audiência. Nesse sentido, atribui-se relevância ao conceito de performance (BAUMAN, 1986; RICHARDS, 1999; OLIVEIRA \& BASTOS, 2001; LANGELIER, 2001; RIESSMAN, 2008), uma vez que nos possibilita compreender as narrativas como atuações dramatúrgicas (GOFFMAN, 2007 [1975]) que dão forma às relações sociais cotidianas.

Os estudos sobre performance já figuram nos trabalhos de Erving Goffman (2007 [1975]) a respeito 
do gerenciamento de impressões do eu face à presença dos outros na interação, de sua plateia. Utilizando-se de uma metáfora dramatúrgica para elaborar sua teorização, Goffman aponta que, no palco interacional da vida em sociedade, o indivíduo espera ser reconhecido por seus atributos morais socialmente valorizados. Assim, embrenha-se na tarefa de comportar-se de tal maneira a transmitir para os outros a impressão sobre si almejada. Ao mesmo tempo, espera que sua plateia leve a sério a impressão sobre si que deseja veicular. Goffman define performance (o desempenho) como "toda atividade de um determinado participante, em dada ocasião, que sirva para influenciar, de algum modo, qualquer um dos outros participantes" (GOFFMAN, 2007 [1975], p.23).

A noção de performance chama atenção para a situacionalidade das narrativas que contamos e para a relevância dos ouvintes na composição e interpretação dessas histórias. As identidades geradas via performance narrativa "são situadas e realizadas tendo a audiência em mente" (RIESSMAN, 2008, p.106). Consequentemente, o imediatismo da performance, da encenação da história, adquire notoriedade, uma vez que traz a ação passada para o aqui e agora da interação. Toda essa perspectiva reconstrói (ou mesmo desconstrói) o que, dentro da nossa cultura, costumamos nomear como "verdade" de uma história. Assim, a noção de performance entende as narrativas como artefatos sociais e a verdade como produto dos intercâmbios face-a-face, em vez de dado "real" empiricamente comprovado.

Ao contar uma história, o narrador vivencia, segundo Riessman (1993, p.20), "um problema fundamental: como convencer o ouvinte que não estava lá de que algo importante aconteceu”. Na tentativa de produzir coerência para seu relato, o narrador recorre a formas retóricas de persuasão a fim de construir conexões afetivas com seu interlocutor. Além disso, lança mão 
de recursos linguísticos de dramatização/performance (RIESSMAN, 2008) a fim de criar factualidade, conferir credibilidade às suas narrativas e estabelecer alinhamento (GOFFMAN, 2002 [1979]) com a plateia. Dentre os recursos que fornecem às narrativas um aspecto dramatúrgico, dialógico e mesmo estratégico (OLIVEIRA \& BASTOS, 2001), merecem atenção a metanarração e o apelo para as emoções.

A metanarração corresponde aos comentários avaliativos acerca da própria narrativa e dos elementos que constituem o evento narrativo (como, por exemplo, os personagens envolvidos na cena). Para Bauman (1986, p.100), a metanarração objetiva "construir uma ponte entre o evento narrado e o evento narrativo, ao atingir faticamente os ouvintes, que se aproximam da história, se identificam com ela e dela participam". Trata-se de um recurso por meio do qual o narrador se mostra para sua plateia da forma como quer ser visto. Ao julgar determinadas ações como justas, absurdas, desagradáveis etc., o narrador evidencia o ponto de sua história e abre espaço para sua construção identitária. Segundo o modelo laboviano, a metanarração figura com uma das formas de avaliação externa: o narrador suspende o fluxo narrativo com o intuito de dirigir-se diretamente para seu ouvinte e emitir um julgamento avaliativo acerca da experiência narrada.

Uma vez que os relatos são, sempre, reconstruções ou replayings pessoais de experiências passadas (GOFFMAN, 2007 [1975]; BASTOS, 2005), faz-se necessário apelar para a carga dramática das histórias e despertar as emoções dos interlocutores como forma de trazê-los para o palco da performance do narrador. Essas conexões afetivas permitem um alinhamento (GOFFMAN, 2002 [1979]) entre narrador e ouvintes e criam um forte sentido de envolvimento. Somos convidados, assim, "a entrar na perspectiva do 
${ }^{1} \mathrm{O}$ termo fonética expressiva aparece em Gumperz (1982) para se referir à gama de "pistas de contextualização" que marcam a fala em interação. A fonética expressiva, as marcas prosódicas paralinguísticas, a alternância de códigos, etc. formam, para Gumperz, um conjunto de instruções potenciais para a força ilocucionária dos enunciados, sendo usadas para comunicar ou inferir propósitos comunicativos.

\footnotetext{
${ }^{2}$ As gravações e transcrições realizadas para o presente estudo foram feitas com base na tradição da Sociolinguística Interacional e da Análise da Conversa Etnometodológica, adaptando-se as convenções de Sacks, Schegloff \& Jefferson (1974) e incorporando-se símbolos sugeridos por Schiffrin (1996) e Tannen (1989): ... para pausa não medida; . para entonação descendente; ?para entonação ascendente; , para entonação de continuidade; sublinhado para ênfase; MAIÚSCULA para muita ênfase; $o$ palavrao para voz baixa; >palavra< para fala mais rápida; <palavra > para
}

narrador" (RIESSMAN, 2008, p.9). Frequentemente, a dramatização das emoções vividas pelo narrador é construída por meio de recursos de avaliação encaixada (LABOV, 1972). O emprego de estruturas repetitivas e paralelísticas, a alternância de tempos verbais, a utilização de fonética ${ }^{1}$ expressiva e alongamento de vogais, o uso de intensificadores lexicais, entre outros, trazem os interlocutores para dentro da história narrada, fazendo-os experienciar, no evento narrativo, as emoções vividas pelo narrador no evento narrado. Além disso, o emprego desses recursos linguísticos contribuem sensivelmente na tessitura da auto-imagem que o narrador espera transmitir, com base em atributos morais socialmente valorizados. A análise a seguir, como se verá, objetiva explorar alguns desses recursos.

A análise narrativa pelo viés da performance afasta-se da mera interpretação de conteúdos das histórias, apropria-se de elementos da análise estrutural e acrescenta outras preocupações. $O$ olhar para a atuação dramatúrgica no palco da vida em sociedade dá visibilidade ao modo como as histórias são contadas e o que elas dizem sobre o narrador e a cultura ou grupo social a que pertence. Ademais, na perspectiva da performance, elementos como o quando e o por quê da narrativa, além dos participantes discursivos e do próprio pesquisador, são incluídos na análise. O olhar para o detalhe na observação e interpretação da experiência narrada em sua complexidade, portanto, é que fará a diferença.

\section{Análise de dados}

Os dados ${ }^{2}$ a serem aqui apresentados foram gerados em situação de entrevista e gravados em áudio com três alunas de uma escola de nível médio-técnico da rede federal de ensino, localizada no município de Nova Iguaçu, Baixada Fluminense. A entrevista foi realizada em 2 de 
outubro de 2009 por uma das pesquisadoras e, na ocasião, Joana, Raquel e Kátia (nomes fictícios) cursavam a última série do curso técnico de nível médio em Enfermagem. $\mathrm{Na}$ transcrição dos dados, conforme convenções típicas do sociointeracionismo, as sequências foram tratadas com refinamento, tanto quanto foi possível ao ouvido, de aspectos linguísticos, paralinguísticos e prosódicos, além do recurso às notas etnográficas. Na sequência transcrita nesta seção, as alunas encenam, via padrões narrativos e recursos formais de performance, as dificuldades vividas pelos alunos dessa escola em termos de preenchimento integral do tempo e de exaustão física. O valor sinalizador de cada um dos mecanismos tornados relevantes na análise que se segue é dependente, conforme Gumperz (1982), do reconhecimento tácito de seus significados por parte dos participantes e analistas.

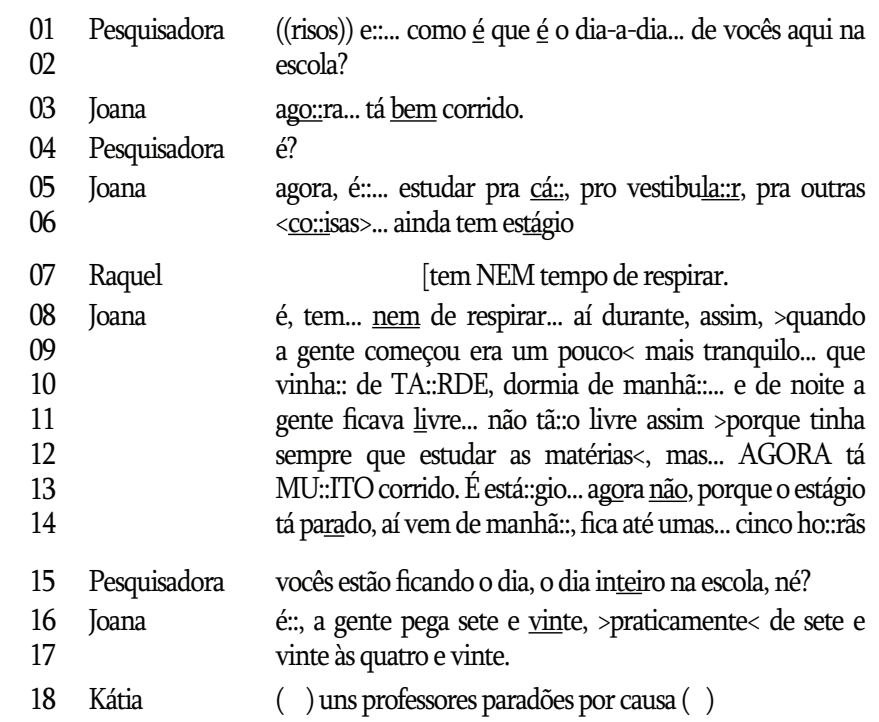

fala mais lenta; :: para alongamentos; [ para sobreposição de fala; ( ) para fala inaudível; (( )) para comentários do analista. O interesse pelos aspectos prosódicos das narrativas sobre as quais nos debruçamos aqui é posterior à geração e ao tratamento dos dados, fato que impossibilita o acréscimo, neste artigo, de evidências empíricas típicas dos estudos prosódicos (tais como as medidas de duração de sílabas, palavras, enunciados) e descrição dos contornos entoacionais. A fim de aprimorarmos a interface aqui proposta entre as duas tradições, reservamos a estudos futuros parcerias que possibilitem análises mais técnicas das marcas prosódicas da fala em interação. 


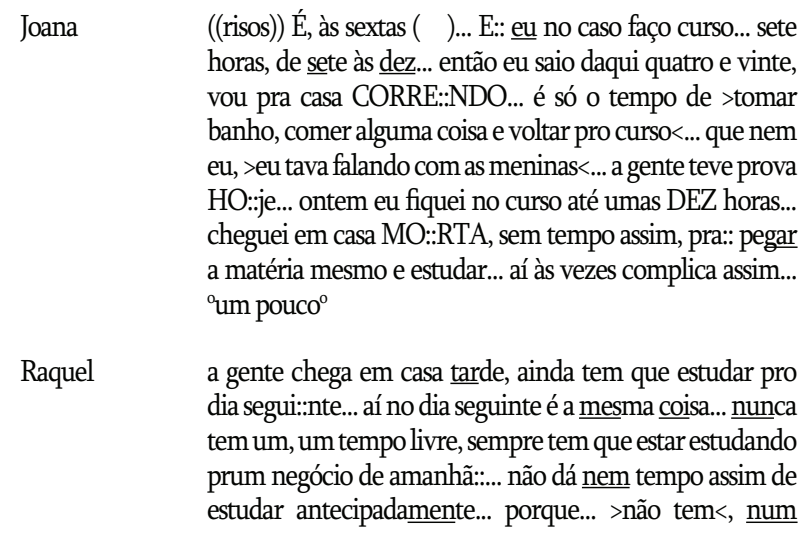
horas, de sete às dez... então eu saio daqui quatro e vinte, vou pra casa CORRE::NDO... é só o tempo de >tomar banho, comer alguma coisa e voltar pro curso<... que nem $\mathrm{eu},>$ eu tava falando com as meninas $<. .$. a gente teve prova HO::je... ontem eu fiquei no curso até umas DEZ horas... cheguei em casa MO::RTA, sem tempo assim, pra:: pegar a matéria mesmo e estudar... aí às vezes complica assim... ${ }^{\circ}$ um pouco ${ }^{\circ}$

Raquel a gente chega em casa tarde, ainda tem que estudar pro dia segui::nte... aí no dia seguinte é a mesma coisa... nunca tem um, um tempo livre, sempre tem que estar estudando prum negócio de amanhã::... não dá nem tempo assim de estudar antecipadamente... porque... > não tem<, num

O ponto da narrativa (a razão de sua reportabilidade) co-construída por Joana e Raquel é a caracterização da exaustão que tipifica o cotidiano dos alunos dessa escola. Dois movimentos narrativos podem ser identificados: um, no sentido de dramatizar esse cotidiano de dificuldades no nível de uma corporeidade; outro, no sentido de construir os estudos como parte da rotina dos alunos em tempo integral. Joana atribui essa intensificação e acúmulo das atividades ao fato de estarem no último ano do curso de Enfermagem, momento em que coincidem as tarefas de sala de aula, o estágio supervisionado na área técnica e o preparo para exames vestibulares em cursos livres realizados fora das dependências da escola. Joana constrói discursivamente uma cisão entre o "antes" e o "momento atual" de sua rotina estudantil, comparando a relativa calmaria de outrora com o turbilhão de atividades do momento presente. Em todos os casos, alguns mecanismos prosódicos, além de outros recursos avaliativos, contribuem para guiar a construção dos sentidos. 
Joana lança mão de recursos de avaliação encaixada para dramatizar essa intensificação de atividades e essa mudança que caracterizam o passado e o presente de sua rotina estudantil. Nas linhas 03 e $08-14$, a aluna faz uso de alongamento de vogais em expressões designadoras de tempo enfatizadas pela altura ("TA::RDE" - linha 10; "manhã::" - linha 10; "Ago::ra" - linha 03). Na passagem do passado para o presente, a aluna emprega, além do alongamento de vogais, o recurso prosódico da ênfase, utilizando-se de fala mais forte no marcador temporal "AGORA" (linha 12) e, também, nos intensificadores "bem" (linha 03) e "MU::ITO" (linha 12).

Assume-se, com Gumperz (1982), que os participantes têm expectativas sobre o que é considerado normal e o que é considerado marcado em termos de ritmo, volume da voz, entoação, estilo, e que esses aspectos marcados devem ser lidos à luz de seus efeitos de sentido na interação. É interessante notar, por exemplo, a construção do passado de Joana e de seus colegas de classe ("a gente" - linha 10) como um momento no qual a passagem do tempo ocorre de modo mais tranquilo e sistemático, havendo períodos delimitados para o descanso corporal ("dormia de manhã::" - linha 10), as obrigações estudantis ("vinha:: de TA::RDE" - linhas 0910) e o tempo destinado a atividades outras, à escolha dos próprios alunos ("de noite a gente ficava livre" - linhas 10-11). Já o presente é construído discursivamente como uma maratona, uma corrida de longo e cansativo percurso 
(“Ago::ra... tá bem corrido" - linha 03; "mas... AGORA tá MU::ITO corrido" - linha 12), todos sinalizados a partir de fonética expressiva e marcas prosódicas. Joana elabora um movimento de ação complicadora, com verbos no presente do indicativo, para caracterizar a rotina diária vivida pela coletividade dos alunos do curso de Enfermagem. Nesse movimento, Joana destaca o longo período de tempo em que permanecem nas dependências da escola, conferindo particular ênfase prosódica aos extremos de um dia comum de aula: de cedo pela manhã até $\mathrm{o}$ fim da tarde.

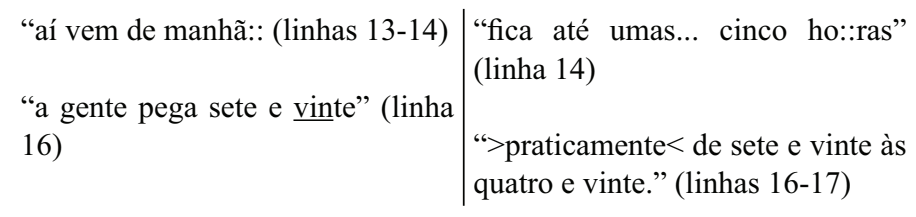

A fim de ratificar o ponto desse movimento narrativo de cunho mais coletivista, Joana constrói duas sub-narrativas, das linhas 19 a 27, nas quais ela própria figura como protagonista. Ao contar uma história sobre si, Joana investe discursivamente na produção e manutenção identitária de seu grupo, de uma coletividade.

1a SUB-NARRATIVA

"eu no caso faço curso... sete horas, de sete às dez" (linha 19)

"então eu saio daqui quatro e vinte" (linha 20)

"vou pra casa CORRE::NDO" (linha 21)

"é só o tempo de >tomar banho," (linhas 21-22)

"comer alguma coisa” (linha 22)

“e voltar pro curso" (linha 22)

2“SUB-NARRATIVA

">eu tava falando com as meninas<" (linha 23)

“a gente teve prova HO::je." (linhas 23-24)

"ontem eu fiquei no curso até umas DEZ horas" (linha 24)

“cheguei em casa MO::RTA" (linha 25)

"sem tempo assim, pra:: pegar a matéria mesmo e estudar" (linhas 25-26) 
Como hábil maratonista, Joana dramatiza a exaustão de seu cotidiano e os impactos do escasso tempo a ela disponível. Novamente, os recursos da ênfase e do alongamento de vogais incidem sobre os marcadores temporais ("de sete às dez" - linha 19; "HO::je" - linha 24; "até umas DEZ horas" - linha 24). O verbo "correr", empregado no gerúndio e com expressiva ênfase e vogal alongada (“CORRE::NDO” - linha 21), encena a velocidade empreendida pela aluna para dar conta do pouco tempo que lhe resta para atos elementares da vida humana, como a higiene pessoal ("tomar banho" - linhas 21-22) e a alimentação ("comer alguma coisa" - linha 22). A maratona percorrida por Joana assume maior vivacidade ao ser empreendida uma maior velocidade de fala na narração desses afazeres realizados de forma apressada: ">tomar banho, comer alguma coisa e voltar pro curso <" (linhas 21-22). O uso do ritmo mais acelerado de fala constrói, no aqui e agora da performance narrativa, a correria vivida por Joana em sua maratona cotidiana como aluna dessa escola. Envolvidos pela carga dramática da performance narrativa de Joana, corremos junto com ela e experienciamos o cansaço narrado.

Em um segundo momento, a aluna elenca Kátia e Raquel, participantes da mesma entrevista, como testemunhas que atestam a veracidade dessas emoções vividas (">eu tava falando com as meninas<" - linha 23) e partilham da visão de que essa exaustão cotidiana pode acarretar consequências problemáticas (por exemplo, fazer uma prova sem ter estudado previamente - linhas 23-24, 25-26). Raquel resgata o ponto da narrativa iniciada por Joana e elabora uma espécie de coda resumitiva relacionada ao cotidiano comum aos alunos como um todo, no qual falta tempo para a quantidade de estudos exigida. 


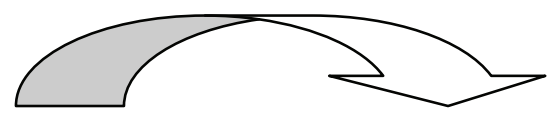

"A gente chega em casa tarde, "aí no dia seguinte é a mesma ainda tem que estudar pro dia coisa” (linha 29) segui::nte" (linhas 28-29)

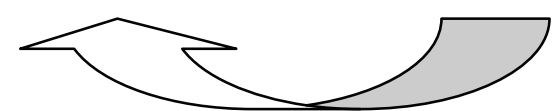

"nunca tem um, um tempo livre" (linhas 29-30)

"sempre tem que estar estudando prum negócio de amanhã::" (linhas 30-31)

Raquel constrói discursivamente um sentido de rotina contínua, um ciclo repetitivo e infindável no qual "sempre" (linha 30) é preciso estudar, apesar de "nunca" (linha 29) haver tempo para isso. Novamente, a ênfase aparece como marca de drama. O cotidiano dos alunos é tecido como um percurso de dificuldades constantes, marcado pelo acúmulo de atividades e pelo sacrifício do tempo. Vale ressaltar o modo como o cansaço e a exaustão são dramatizados como uma dolorida experiência corpórea. O verbo "correr" (linhas 03, 12 e 21), marcado por dispositivos de avaliação encaixada - tais como o alongamento de vogais e a fala enfática empregada no próprio verbo ou nos intensificadores lexicais -, imprime ritmo e velocidade aos afazeres de Joana. A escassez de tempo é construída, por Joana e Raquel, como noção impactante para um processo elementar para os seres vivos, que é a respiração. As alunas conferem um aspecto fortemente dramático do acúmulo de afazeres, como se a energia necessária para a continuidade de suas rotinas fosse prejudicada pela falta de tempo: "tem NEM tempo de respirar." - linha 07). Assim, atinge-se o nível mais extremo da exaustão corpórea: "cheguei em casa MO::RTA" (linha 25). O sentido de morte física, resultado do cansativo ritmo característico do dia-a-dia dessas alunas, é construído discursivamente pelo emprego de 
prosódia expressiva. Para Joana e Raquel, o (per)curso de dificuldades é vivido não somente no nível simbólico, mas também no corpo. Na performance narrativa construída, corre-se, perde-se o ar e morre-se.

Neste ponto, importa lembrar a forte inter-relação entre performance narrativa e construção de identidades. Narrar é, também, construir um self, uma auto-imagem, em conformidade com os valores morais e atributos sóciohistoricamente validados pelo grupo social no qual a história foi contada. A rotina de exaustão física, construída principalmente por elementos prosódicos na narrativa acima transcrita, encena uma performance de dor, sacrifício e martírio que tipificam o percurso estudantil das alunas. A aceleração dos afazeres, a escassez do tempo e o acúmulo crescente de atividades que levam à exaustão corporal são signos do valor atribuído à luta e dedicação investidas por essas alunas. Fundamentada no caráter honroso atribuído à luta e ao sacrifício (OLIVEIRA, 2012) típico de boa parte das camadas populares (grupo social do qual fazem parte as alunas), constrói-se, assim, uma retórica de dor e sacrifício, devidamente sublinhada pelos aspectos suprassegmentais da narrativa.

\section{Considerações finais}

Iniciamos este artigo observando de que maneira elementos prosódicos têm estado presentes na reflexão interacionista a partir dos conceitos de pistas de contextualização (GUMPERZ, 1982) e avaliação encaixada (LABOV, 1972). Com base nos recursos precários disponibilizados pelos estudos de narrativas conversacionais no que diz respeito à captação e análise dos fenômenos prosódicos e paralinguísticos, procuramos argumentar que a superação das dificuldades é construída discursivamente como uma performance de obstinação, que enobrece identitariamente o aluno que "vai à luta" e 
vence as dificuldades colocadas diante dele. Para isso, a exaustão e o drama são recriados performativamente não apenas pelo conteúdo de que se compõem as histórias, mas também, e quiçá principalmente, pela forma que contorna aquilo que será tornado relevante. Nesse processo, os mecanismos suprassegmentais adquirem importância especial: ritmo, pausas, entoação, altura e alongamentos são estrategicamente combinados à sequência narrativa como recurso expressivo da avaliação que as alunas fazem de si e de sua rotina.

A esta altura, esperamos ter mostrado, mesmo que sumariamente, como se dão os processos de interpretação das pistas prosódicas em análises que exploram a performance narrativa e seus modos de construir expectativas e fornecer sentido à experiência e às identidades sociais. Com sorte, este artigo terá evidenciado o vasto-e largamente inexplorado-potencial latente na aproximação entre, de um lado, os estudos discursivos e identitários, e, de outro, as investigações que se debruçam sobre a análise prosódica da fala espontânea. Este trabalho terá cumprido seu papel se contribuir para o aprofundamento do diálogo entre os dois campos. 


\section{Referências}

BASTOS, L. C. Narrativa e vida cotidiana. Scripta, vol. 7, n ${ }^{\circ}$. 14, p.118-127, 2004.

Contando estórias em contextos espontâneos e institucionais - uma introdução ao estudo da narrativa. Calidoscópio. Vol. 3, nº. 2, p. 74-87, 2005.

BAUMAN, R. Story, performance and event: contextual studies of oral narrative. Cambridge: Cambridge University Press, 1986.

BRUNER, J. Atos de significação. Porto Alegre: Artes Médicas, 1997.

GOFFMAN, E. Footing. In: RIBEIRO, B. T.; GARCEZ, P. M. Sociolinguística Interacional. São Paulo: Edições Loyola, 2002 [1979].

A representação do eu na vida cotidiana. Petrópolis, RJ: Vozes, 2007 [1975].

GUMPERZ, J. Discourse strategies. Cambridge: Cambridge University Press, 1982.

JOHNSTONE, B. Discourse analysis and narrative. In: SCHIFFRIN, D.; TANNEN, D.; HEIDI, E. H. (Orgs.) The handbook of discourse analysis. Blackwell, 2001.

LABOV, W. The transformation of experience in narrative syntax. In: __ Language in the inner city. Philadelphia: University of Pennsylvania Press, 1972.

LANGELIER, K. M. 'You're marked': breast cancer, tattoo, and the narrative performance of identity. In: BROCKMEIER, J.; CARBAUGH, D. Narrative and Identity: studies in autobiography, self and culture. Amsterdam: John Benjamins, 2001. 
MOITA LOPES, L. P. Práticas narrativas como espaço de construção das identidades sociais: uma abordagem socioconstrucionista. In: TELLES RIBEIRO, B.; COSTA LIMA, C.; LOPES DANTAS, M. T. (Orgs.) Narrativa, identidade e clínica. Rio de Janeiro: Edições IPUB/CUCA, 2001.

OLIVEIRA, M. The role of pause occurrence and pause duration in the signaling of narrative structure. Advances in Natural Language Processing (proceedings of the 3rd. International Conference Portal), Portugal, 2002.

OLIVEIRA, M. C. L.; BASTOS, L. C. Saúde, doença e burocracia: pessoas e dramas no atendimento de um seguro saúde. In: RIBEIRO, B. T.; LIMA, C. C.; DANTAS, M. T. L. (Orgs.) Narrativa, Identidade e Clínica. Rio de Janeiro: Edições IPUB, 2001.

OLIVEIRA, T. Educação e ascensão social: performances narrativas de alunos da rede pública federal na Baixada Fluminense. 2012. 279f. Tese (Doutorado em Estudos da Linguagem) - Departamento de Letras, Pontifícia Universidade Católica do Rio de Janeiro, 2012.

RICHARDS, K. Working towards common understandings: collaborative interaction in staffroom stories. Text 19 (1), pp. 143-174, 1999.

RIESSMAN, C. K. Narrative Analysis. Newbury Park: Sage, 1993.

Narrative Methods for the Human Sciences. Los Angeles: Sage Publications, 2008.

SACKS, H.; SCHEGLOFF, E. A.; JEFFERSON, G. A simplest systematics for the organization of turn-taking for conversation. Language. Vol. 50, No. 4, Part 1. Dec., 1974.

SCHIFFRIN, D. Narrative as self-portrait: sociolinguistic constructions of identity. Language in society. 25: 167-203, 1996. 
TANNEN, D. Talking voices: repetition, dialogue and imagery in conversational discourse. In: Studies in Interactional Sociolinguistics 6. Cambridge: Cambridge University Press, 1989.

[Recebido em 31 de agosto de 2013 e aceito para publicação em 30 de novembro de 2013] 